\section{Orthostatic Tremor}

Anna DePold Hohler ${ }^{1}$ and Marcus Ponce de Leon $^{2}$

${ }^{1}$ Boston University Medical Center, Boston, MA, USA

${ }^{2}$ William Beaumont Army Medical Center, El

Paso, TX, USA

\section{Synonyms}

Standing tremor

\section{Definition}

Orthostatic tremor is considered to be a variant of essential tremor. This type of tremor occurs in the legs immediately on standing and is relieved by sitting down. It is usually of high frequency, and no other clinical signs and symptoms are present.

\section{Cross-References}

Tremor

\section{References and Readings}

Jankovic, J. (2007). Tremor and Myorhythmia. In S. Fahn \& J. Jankovic (Eds.), Principles and practice of movement disorders (pp. 451-479). Philadelphia: Churchill Livingstone Elsevier. 